\title{
Particle Coating-Dependent Interaction of Molecular Weight Fractionated Natural Organic Matter: Impacts on the Aggregation of Silver Nanoparticles
}

\author{
Yongguang Yin, ${ }^{\dagger}$ Mohai Shen, ${ }^{\dagger}$ Zhiqiang Tan, ${ }^{\dagger}$ Sujuan Yu, ${ }^{\dagger}$ Jingfu Liu, ${ }^{* \dagger}$ and Guibin Jiang ${ }^{\dagger}$ \\ ${ }^{\dagger}$ State Key Laboratory of Environmental Chemistry and Ecotoxicology, Research Center for Eco-Environmental Sciences, Chinese \\ Academy of Sciences, P.O. Box 2871, Beijing 100085, China
}

\section{Supporting Information}

\begin{abstract}
Ubiquitous natural organic matter (NOM) plays an important role in the aggregation state of engineered silver nanoparticles (AgNPs) in aquatic environment, which determines the transport, transformation, and toxicity of AgNPs. As various capping agents are used as coatings for nanoparticles and NOM are natural polymer mixture with wide molecular weight (MW) distribution, probing the particle coating-dependent interaction of MW fractionated natural organic matter $\left(\mathrm{M}_{\mathrm{f}} \mathrm{NOM}\right)$ with various coatings is helpful for understanding the differential aggregation and transport behavior of engineered AgNPs as well as other metal nanoparticles. In this study, we investigated the role of pristine and $\mathrm{M}_{\mathrm{f}} \mathrm{NOM}$ on the aggregation of AgNPs with Bare, citrate, and PVP coating (Bare-, Cit-, and PVP-AgNP) in mono- and divalent electrolyte solutions. We observed that the enhanced aggregation or dispersion of AgNPs in NOM solution highly depends on the coating of AgNPs.

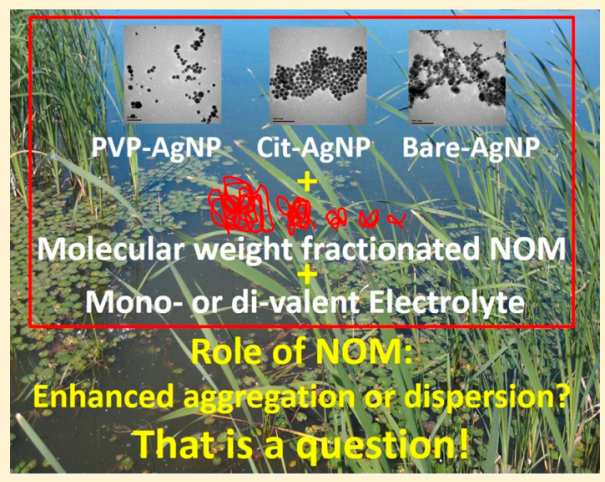
Pristine NOM inhibited the aggregation of Bare-AgNPs but enhanced the aggregation of PVP-AgNPs. In addition, $\mathrm{M}_{\mathrm{f}}-\mathrm{NOM}$ fractions have distinguishing roles on the aggregation and dispersion of AgNPs, which also highly depend on the AgNPs coating as well as the MW of $\mathrm{M}_{\mathrm{f}} \mathrm{NOM}$. Higher MW $\mathrm{M}_{\mathrm{f}} \mathrm{NOM}$ ( $>100 \mathrm{kDa}$ and 30-100 kDa) enhanced the aggregation of PVP-AgNPs in mono- and divalent electrolyte solutions, whereas lower MW $\mathrm{M}_{\mathrm{f}} \mathrm{NOM}(10-30 \mathrm{kDa}, 3-10 \mathrm{kDa}$ and $<3 \mathrm{kDa})$ inhibited the aggregation of PVP-AgNPs. However, all the $\mathrm{M}_{\mathrm{f}} \mathrm{NOM}$ fractions inhibited the aggregation of Bare-AgNPs. For PVP- and BareAgNPs, the stability of AgNPs in electrolyte solution was significantly correlated to the MW of $\mathrm{M}_{\mathrm{f}} \mathrm{NOM}$. But for Cit-AgNPs, pristine NOM and $\mathrm{M}_{\mathrm{f}} \mathrm{NOM}$ has minor influence on the stability of AgNPs. These findings about significantly different roles of $\mathrm{M}_{\mathrm{f}} \mathrm{NOM}$ on aggregation of engineered AgNPs with various coating are important for better understanding of the transport and subsequent transformation of AgNPs in aquatic environment.
\end{abstract}

\section{INTRODUCTION}

The widely use of silver nanoparticles (AgNPs) in consumer and health care products ${ }^{1}$ and inevitable releasing of AgNPs into surrounding environments ${ }^{2-6}$ have increased great concern about the environmental safety of AgNPs. Once entering aquatic environment, AgNPs could undergo profound physical and chemical transformations, including aggregation, sedimentation, adsorption, oxidative dissolution, sulfidation, and rereduction, which have great impacts on the fate, transport, and toxicity of AgNPs.

Natural organic matter (NOM), which is ubiquitous in aquatic environment, plays an important role in the physical and chemical transformation of AgNPs. NOM in natural waters could adsorb on the surface of AgNPs and displace the original capping agents of AgNPs such as polyvinylpyrrolidone (PVP) and citrate. ${ }^{8}$ Usually, the charge and steric effects provided by the adsorbed NOM on AgNPs surface could disperse and cause a partial disaggregation of AgNPs aggregates. ${ }^{9}$ NOM could also inhibit the aggregation of AgNPs induced by ionic strength or specific cations ( such as $\mathrm{Ca}^{2+}$ and $\mathrm{Mg}^{2+}$ ), leading to more stable AgNPs suspension. ${ }^{10-14}$ Whereas, in solutions with high $\mathrm{Ca}^{2+}$ concentration, the presence of NOM contributed to the enhanced aggregation of AgNPs, possibly due to intermolecular bridging with the NOM. ${ }^{15}$ However, as NOM is a polydispersed mixture of natural polymers with molecular weight (MW) from less than $100 \mathrm{Da}$ to over $300 \mathrm{kDa}^{16}$ it is still not well understood how a specific fraction of NOM acting on the dispersion of AgNPs. Recent results by Louie et al. ${ }^{17}$ and our previous study ${ }^{18}$ revealed that MW fractionated NOM $\left(\mathrm{M}_{\mathrm{f}}\right.$ NOM) has drastically different stabilizing effects toward gold and fullerene nanoparticles against electrolytes-induced aggregation. As for AgNPs, it was also demonstrated that humic acid fraction has greater capability than fulvic acid fraction in enhancing the transport of AgNPs by reducing their aggregation and deposition. ${ }^{19}$ In our previous study, we observed that high MW Suwannee River NOM plays more significant role in stabilizing NOM-reduced AgNPs in the

Received: December 16, 2014

Revised: April 29, 2015

Accepted: May 5, 2015

Published: May 5, 2015 
presence of $\mathrm{Ca}^{2+}$ than low MW NOM. ${ }^{20}$ These findings further highlighted the importance of the distinguishing roles of different NOM fractions in the transport and subsequent chemical transformation and toxicity of engineered AgNPs. However, in commercial AgNPs products, AgNPs are often modified with various capping agents or coatings, which make the interaction between AgNPs and NOM more complicated. Generally, the electrostatic interaction, steric hindrance or electrosteric repulsion imparted by various capping agents could enhance the colloidal stability of AgNPs in aqueous solutions, especially in solutions of high ionic strength, ${ }^{21}$ and thus govern the transport of AgNPs in porous media. ${ }^{22}$ Although the difference of various coating agents (such as PVP and citrate) in stabilizing of AgNPs has been investigated in recent years, ${ }^{21-25}$ the synergetic effect of AgNPs coating and $\mathrm{M}_{\mathrm{f}} \mathrm{NOM}$ on the aggregation and dispersion of AgNPs are largely unknown. Probing the particle coating-dependent interaction of $\mathrm{M}_{\mathrm{f}} \mathrm{NOM}$ is helpful for understanding the differential aggregation and transport behavior of engineered AgNPs as well as other metal nanoparticles with various coatings.

The objectives of this research were (i) to evaluate the differential influences of coating agents on the aggregation kinetics of AgNPs in electrolyte solutions with or without pristine NOM; (ii) to elucidate the role of $\mathrm{M}_{\mathrm{f}} \mathrm{NOM}$ on the aggregation kinetics of AgNPs with different coating agents in mono/divalent electrolyte solutions; and (iii) to assess possible environmental implications of the key factors (such as MW of NOM and nature of coating agents) on the aggregation and subsequent transport of AgNPs in aquatic compartment. To this end, Bare, citrate, and PVP coated AgNPs were adopted as models of AgNPs to study the effect of $\mathrm{M}_{\mathrm{f}}-\mathrm{NOM}$ on the aggregation kinetics of AgNPs in mono- and divalent electrolyte solutions.

\section{MATERIALS AND METHODS}

Materials. $\mathrm{AgNO}_{3}$ (>99.5\%) and hydroxylammonium chloride $(>98.5 \%)$ were purchased from Sinopharm Chemicals (Shanghai, China). Polyvinylpyrrolidone (PVP, MW = 58 000) was from Aladdin Chemistry Co. Ltd. (Shanghai, China). Suwannee River natural organic matter (SRNOM) (1R101N) was obtained from the International Humic Substance Society (St. Paul, MN). Amicon Ultra-15 centrifugal filter (with $3 \mathrm{kDa}$, $10 \mathrm{kDa}, 30 \mathrm{kDa}$, and $100 \mathrm{kDa}$ nominal $\mathrm{MW}$ cutoff, respectively) from Millipore (Darmstadt, Germany) were used for fractionation of SRNOM. The other reagents were purchased from Beijing Chemicals (Beijing, China). All the reagents were used as obtained without further purification. Ultrapure water $(18.3 \mathrm{M} \Omega$ ) produced with a Milli-Q Gradient system (Millipore, Bedford) was used throughout the experiments.

Fractionation and Characterization of NOM. $\mathrm{M}_{\mathrm{f}} \mathrm{NOM}$ was prepared using Amicon Ultra-15 centrifugal filters with different MW cutoff. The detailed procedure of ultrafiltration and the characterization of pristine and $\mathrm{M}_{\mathrm{f}} \mathrm{NOM}$ were given in our previous study. ${ }^{18,20}$ Briefly, the stock solution of SRNOM was first loaded and centrifuged (30 min at $3743 \mathrm{~g}$ ) using Amicon Ultra-15 centrifugal filters $(100 \mathrm{kDa})$. The filtrate was then collected and filtered sequentially by $30 \mathrm{kDa}, 10 \mathrm{kDa}$ and $3 \mathrm{kDa}$ filters at centrifuging rates 5095, 6654, and 8422g, respectively. The retentate or filtrate was collected as $\mathrm{M}_{\mathrm{f}}-\mathrm{NOM}$ (>100 kDa, 30-100 kDa, 10-30 kDa, 3-10 kDa, and <3 kDa, respectively). Concentrations of pristine $S R N O M$ and $M_{f-}$
NOM were measured by a Teledyne Tekmar Total Organic Carbon (TOC) Fusion Analyzer (Mason, OH). The UV-vis and fluorescence excitation-emission spectra were recorded on an UV-vis-NIR spectrometer (UV-3600, Shimadzu, Japan) and a fluorescence spectrometer (FluoroMax-4, Horiba, Edison, NJ), respectively.

Preparation of AgNPs. PVP-AgNPs were synthesized following our previous report. ${ }^{26}$ Briefly, $10 \mathrm{mmol} \mathrm{L}^{-1} \mathrm{AgNO}_{3}$ $(10 \mathrm{~mL})$ was added into a $90 \mathrm{~mL}$ solution containing 1.67 mmol L ${ }^{-1}$ hydroxylammonium chloride and $3.33 \mathrm{mmol} \mathrm{L}^{-1}$ $\mathrm{NaOH}$ under vigorous stirring. After several minutes, $0.3 \mathrm{~g}$ PVP was added and the resulting solution was stirred overnight. AgNPs were purified by centrifugal ultrafiltration (Amicon Ultra-15 $100 \mathrm{kDa}$, Millipore) to remove PVP and silver ion and the resulting AgNPs solution was stored at $4{ }^{\circ} \mathrm{C}$ in the dark for later use.

Bare-AgNPs were synthesized following literature ${ }^{27}$ with slightly modification. Briefly, ice-cold $1 \mathrm{mmol} \mathrm{L}^{-1} \mathrm{AgNO}_{3}(50$ $\mathrm{mL}$ ) was dripped slowly into $100 \mathrm{~mL} 2 \mathrm{mmol} \mathrm{L}^{-1}$ sodium borohydride solution under magnetic stirring in an ice bath. The resulting AgNPs solution was magnetically stirred while it was allowed to warm to room temperature. Owning to the residue borate ion on the AgNP, the AgNPs solution is stable over 2 months.

Citric acid-stabilized $20 \mathrm{~nm}$ AgNP (Cit-AgNP) was purchased from Sigma-Aldrich (article No. 730793, $25 \mathrm{~mL}$, Seelze, Germany).

Characterization of AgNPs. The concentration of AgNPs stock solution was measured by inductively coupled plasma mass spectrometry (ICP-MS, Agilent 7700, Santa Clara, CA) after $\mathrm{HNO}_{3}$ digestion. Transmission electron microscope (TEM) analysis was carried out with an H-7500 (Hitachi, Japan) at $80 \mathrm{kV}$. TEM samples were prepared by dropping $5 \mu \mathrm{L}$ AgNPs suspension onto carbon-coated copper grid and drying at room temperature. The size distribution of the AgNPs was estimated using Nano Measurer 1.2 software and Gaussian fitting. At least 150 particles were counted from multipicture in each case. The UV-vis spectra from 200 to $800 \mathrm{~nm}$ were obtained by using a UV-3600 UV-vis-NIR spectrometer. The zeta potential was measured by dynamic light scattering (DLS) with Zetasizer Nano (ZEN3600, Malvern Instruments, Worcestershire, UK). The PVP content in PVP-AgNP suspension was measured by a Teledyne Tekmar TOC analyzer according to literature. ${ }^{21}$ The AgNP solution was also characterized by X-ray photoelectron spectroscopy (XPS). For XPS analysis, the solution was dropped on Si wafer and dried in the vacuum desiccators at room temperature. The XPS characterization was carried out in an ESCALAB 250 spectrometer (Thermo Scientific, UK) using monochromatic $\mathrm{Al} \mathrm{K} \alpha$ radiation of energy $1486.6 \mathrm{eV}$. Core level binding energies were determined and corrected for substrate charging using $\mathrm{C} 1 \mathrm{~s}$ peak at $284.8 \mathrm{eV}$ as the reference.

Zeta Potential Measurements. The zeta potential of AgNPs in various electrolyte solution conditions was measured using Zetasizer Nano at $25^{\circ} \mathrm{C}$. The zeta potential of AgNPs in NOM-free electrolyte solutions was measured at a range of $\mathrm{NaClO}_{4}$ and $\mathrm{Ca}\left(\mathrm{ClO}_{4}\right)_{2}$ concentrations in $1 \mathrm{mmol} \mathrm{L}^{-1}$ borate buffer ( $\mathrm{pH}$ 7.4). Changes in the zeta potential of AgNPs in the presence of pristine- and $\mathrm{M}_{\mathrm{f}}-\mathrm{NOMs}$ were measured at 100 and $500 \mathrm{mmol} \mathrm{L}^{-1}$ for $\mathrm{NaClO}_{4}, 5$ and $20 \mathrm{mmol} \mathrm{L}^{-1}$ for $\mathrm{Ca}\left(\mathrm{ClO}_{4}\right)_{2}$, respectively.

Aggregation Kinetics of AgNPs by Time-Resolved DLS. Time-resolved (TR)-DLS measurements were performed 

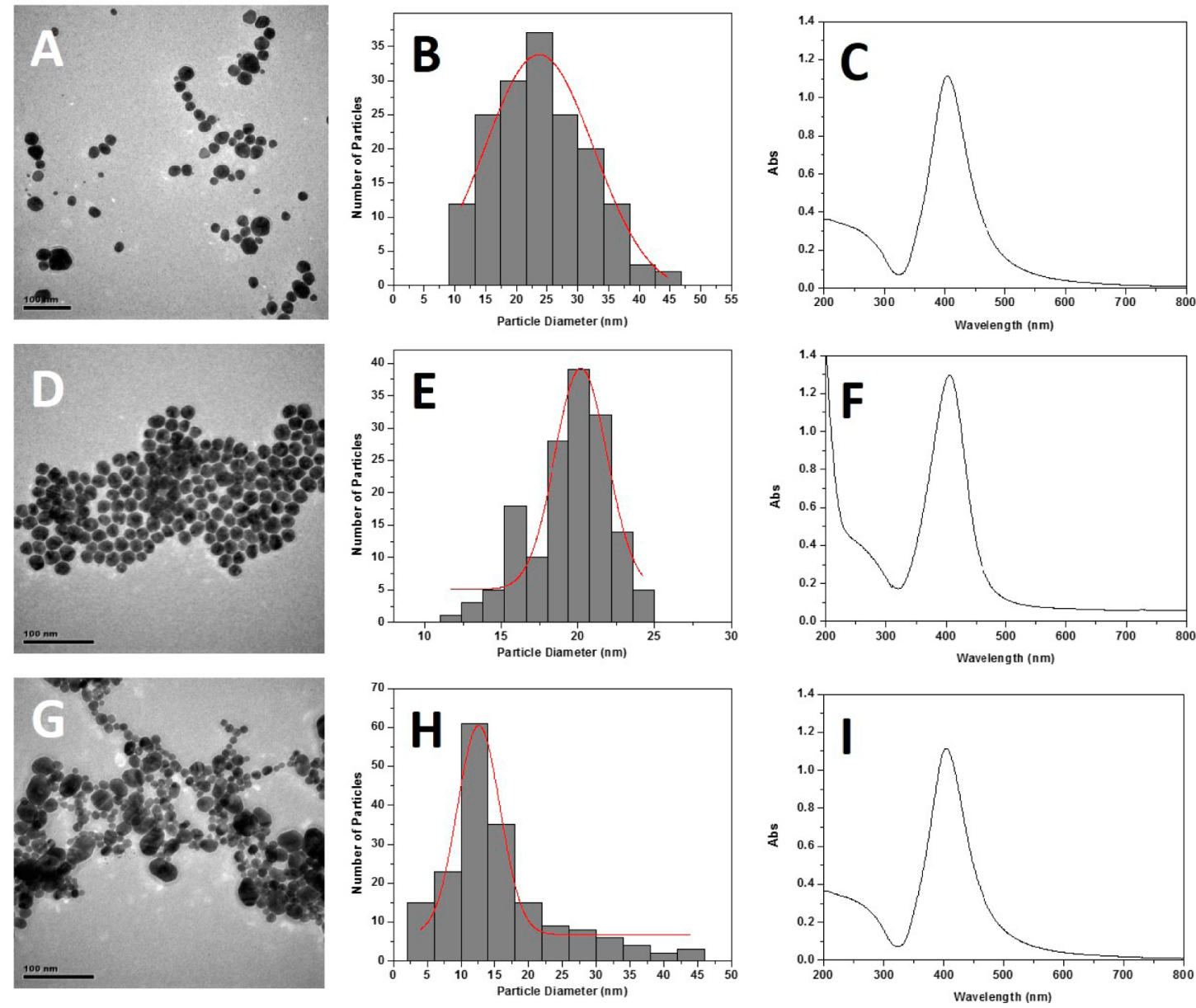

Figure 1. TEM images (A, D, G), size distribution (B, E, H), and UV-visible absorption spectra (C, F, I) of PVP-AgNPs, Cit-AgNPs, and BareAgNPs. (A-C) PVP-AgNPs, (D-F) Cit-AgNPs, and (G-I) Bare-AgNPs. The concentration of AgNPs for UV-visible spectrometry characterization is $10 \mathrm{mg} \mathrm{Ag} \mathrm{L}$.

on a ZEN3600 Zetasizer Nano with $633 \mathrm{~nm}$ red laser and detection angle of $173^{\circ}$. The aggregation kinetics of AgNPs was first tested in mono/divalent electrolyte solutions without NOM. To investigate the effects of $\mathrm{M}_{\mathrm{f}} \mathrm{NOMs}$ on AgNPs aggregation, the pristine- or $\mathrm{M}_{\mathrm{f}} \mathrm{NOM}$ was added into the AgNPs dispersion in polystyrene cuvettes (Sarstedt, Germany). Then monovalent electrolyte $\left(\mathrm{NaClO}_{4}\right)$ or divalent electrolyte $\left(\mathrm{Ca}\left(\mathrm{ClO}_{4}\right)_{2}\right)$ was added into the cuvette to initiate AgNPs aggregation. The $\mathrm{pH}$ of all samples was adjusted to 7.4 with 1 $\mathrm{mmol} \mathrm{L} \mathrm{L}^{-1}$ borate buffer. For each sample, the final volume was $1 \mathrm{~mL}$, with $2 \mathrm{mg} \mathrm{L}^{-1} \mathrm{AgNPs}$ and $1 \mathrm{mg} \mathrm{C} \mathrm{L}^{-1} \mathrm{NOM}$. The details for the TR-DLS measurements, calculation methods for attachment efficiency $(\alpha)$ and critical coagulation concentration (CCC) are given in our previous study. ${ }^{18}$ Briefly, the temperature was set at $25{ }^{\circ} \mathrm{C}$ and measurement position was set as $4.65 \mathrm{~mm}$ from the bottom of the cuvette. The accumulation time based on autocorrelation function was 10 $\mathrm{s}$, and $1 \mathrm{~s}$ delay was set between each measurement. The attachment efficiency, representing the relative aggregation rate, is calculated by normalizing the aggregation rate constant obtained in the solution $(k)$ to the diffusion-limited aggregation rate constant in the absence of NOM in the same electrolyte $\left(k_{\text {fast }}\right)$ :

$$
\alpha=\frac{k}{k_{\text {fast }}}=\frac{\frac{1}{N_{0}}\left(\frac{\mathrm{d} D_{h}(t)}{\mathrm{d} t}\right)_{t \rightarrow 0}}{\frac{1}{\left(N_{0}\right)_{\text {fast }}}\left(\frac{\mathrm{d} D_{h}(t)}{\mathrm{d} t}\right)_{t \rightarrow 0, \text { fast }}}
$$

in which, $D_{\mathrm{h}}$ was the hydrodynamic diameter of AgNPs at time $t$, and $N_{0}$ the initial AgNPs concentration. As all samples used in the TR-DLS measurement contained the same AgNPs concentration, $\left(N_{0}\right)_{\text {fast }}$ was equal to $N_{0}$ in our study. The CCC was calculated by extrapolations of the linear regression of $\alpha$ values in both reaction-limited and diffusion-limited regimes to electrolyte concentration.

Force Analysis by Atomic Force Microscopy. Interaction force measurements were performed using atomic force microscopy (AFM, Multimode8, Bruker) with the tapping mode at room temperature. It should be noted that it is difficult to pick up or immobilize the AgNP to perform surface force measurements, and therefore the force analysis was performed in NOM solution with $\mathrm{SiN}$ probe and silver foil substrate as alternatives. ${ }^{28}$ Data was collected in the presence of NOM at $\mathrm{pH}$ 7.4.

\section{RESULTS AND DISCUSSION}

Characterizations of $\mathrm{M}_{\mathrm{f}}-\mathrm{NOMs}$ and PVP-, Cit-, and Bare-AgNPs. The MW distribution, UV-vis spectroscopy and fluorescence excitation-emission spectroscopy of $\mathrm{M}_{\mathrm{f}} \mathrm{NOMs}$ 

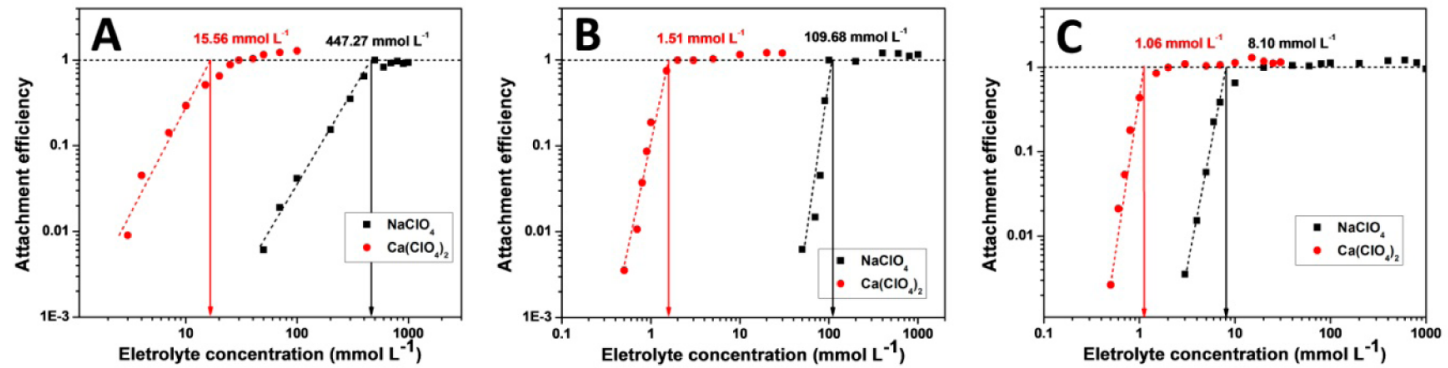

Figure 2. Attachment efficiencies of PVP-AgNPs (A), Cit-AgNPs (B) and Bare-AgNPs (C) as a function of background electrolyte concentration of $\mathrm{NaClO}_{4}$ and $\mathrm{Ca}\left(\mathrm{ClO}_{4}\right)_{2}$ in the absence of NOM. The error bars represent the standard deviation from triplicate measurements. The critical coagulation concentration (CCC) values were also marked.
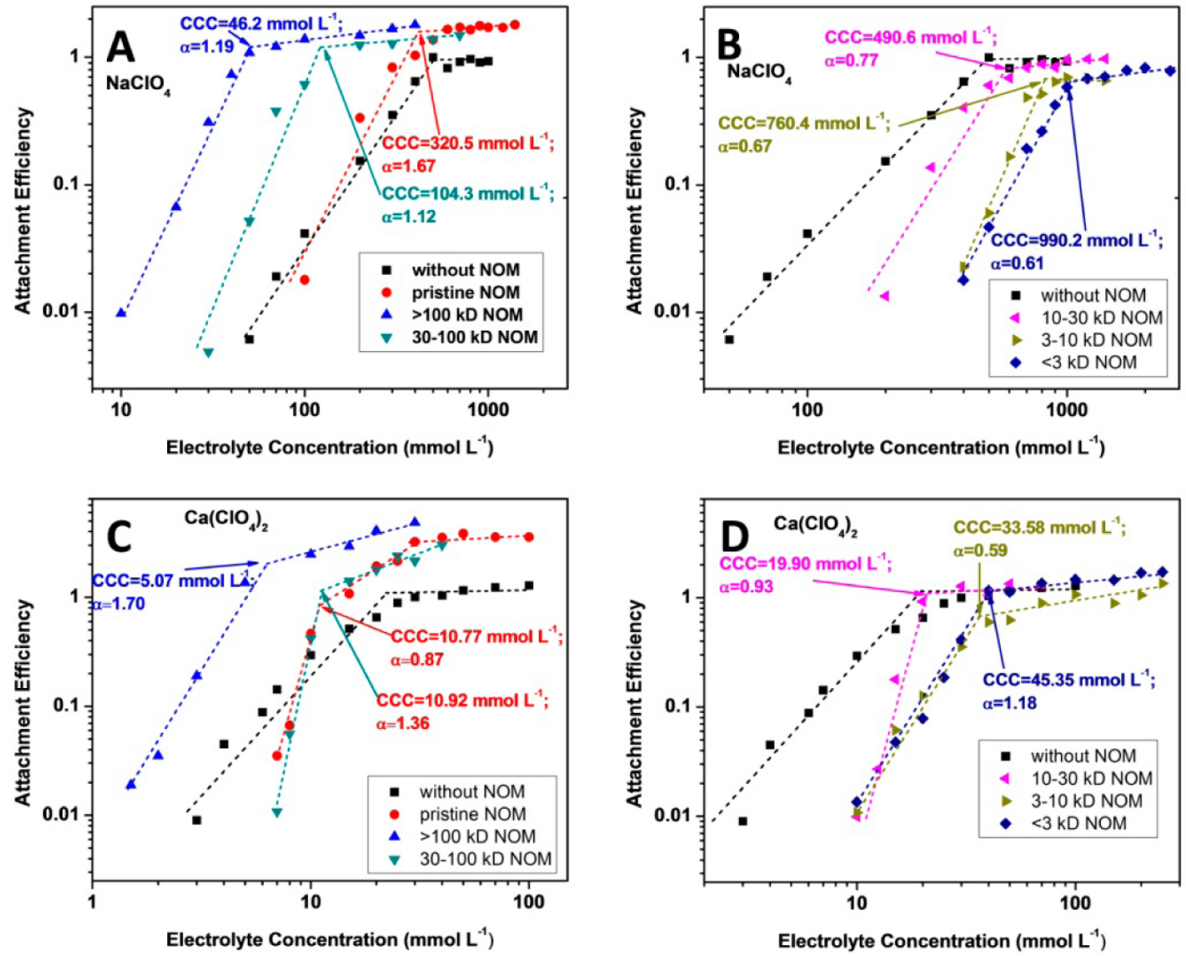

Figure 3. Attachment efficiency of PVP-AgNPs as a function of $\mathrm{NaClO}_{4}(\mathrm{~A}, \mathrm{~B})$ and $\mathrm{Ca}\left(\mathrm{ClO}_{4}\right)_{2}$ (C, D) concentration in the presence of pristine$\mathrm{NOM}$ and $\mathrm{M}_{\mathrm{f}}-\mathrm{NOMs}$. Data for "without NOM" are given to facilitate the comparison of differences of $\alpha$ values among no SRNOM, pristine- and $\mathrm{M}_{\mathrm{f}}$ NOM solutions.

prepared by ultrafiltration was characterized in our previous study. ${ }^{20}$ Generally, the molar absorptivity at $280 \mathrm{~nm}$ increased with the increasing of MW, indicating the abundances of aromatic moiety in higher MW $\mathrm{M}_{\mathrm{f}} \mathrm{NOMs}$. In addition, the maximum intensity of fluorescence peaks (in the range of 350/ $452-370 / 468 \mathrm{~nm}$ ) increased as the $\mathrm{MW}$ of $\mathrm{M}_{\mathrm{f}}-\mathrm{NOM}$ decreased, suggesting the abundances of carboxylic moiety in lower MW $\mathrm{M}_{\mathrm{f}}$-NOMs. ${ }^{29}$ This result is consistent with previous study that high MW fractions of NOM contain more aromatic and aliphatic structure and low MW fractions contain more hydrophilic carboxyl groups. ${ }^{30-32}$

Figure 1 shows the characterizations of the PVP-, Cit-, and Bare-AgNPs used in this study. TEM image (Figure 1A, D, G) and the size distribution (Figure 1B, E, H)showed that the AgNPs are spherical with an average diameter of $23.7 \pm 4.4 \mathrm{~nm}$, $19.5 \pm 2.8 \mathrm{~nm}$ and $13.1 \pm 1.7 \mathrm{~nm}$ for PVP-, Cit- and BareAgNPs, respectively. The UV-vis analysis (Figure 1C, F, I) shows the characteristic surface plasmon resonance (SPR) of AgNPs at 404, 405, and $390 \mathrm{~nm}$ for PVP-, Cit- and Bare-
AgNPs, respectively. The XPS spectra of PVP- and Cit-AgNP (Supporting Information Figure S1 and S2) suggested the presence of coating agents (PVP and citrate) in PVP- and CitAgNP colloids. ${ }^{33,34}$ The signal of boron was observed in the XPS spectra of Bare-AgNP (Supporting Information Figure S3), demonstrating the occurrence of borate in the silver colloids, which was possibly derived from the decomposition of $\mathrm{KBH}_{4}$.

Aggregation of AgNPs in Electrolyte Solution without NOM. The aggregation kinetics of PVP-, Cit-, and Bare-AgNPs in $\mathrm{NaClO}_{4}$ and $\mathrm{Ca}\left(\mathrm{ClO}_{4}\right)_{2}$ electrolytes are given in Figure 2. The aggregation behavior of PVP-, Cit-, and Bare-AgNPs in both $\mathrm{NaClO}_{4}$ and $\mathrm{Ca}\left(\mathrm{ClO}_{4}\right)_{2}$ solutions followed DerjaguinLandau-Verwey-Overbeek (DLVO) theory, with reactionlimited regime $(\alpha<1)$ at lower concentration electrolyte and diffusion-limited regime $(\alpha=1)$ at high concentration electrolyte. This suggested that electrostatic interaction play important role in the stabilization of PVP-, Cit- and BareAgNPs. ${ }^{21}$ The CCCs, derived by intersection of extrapolations 

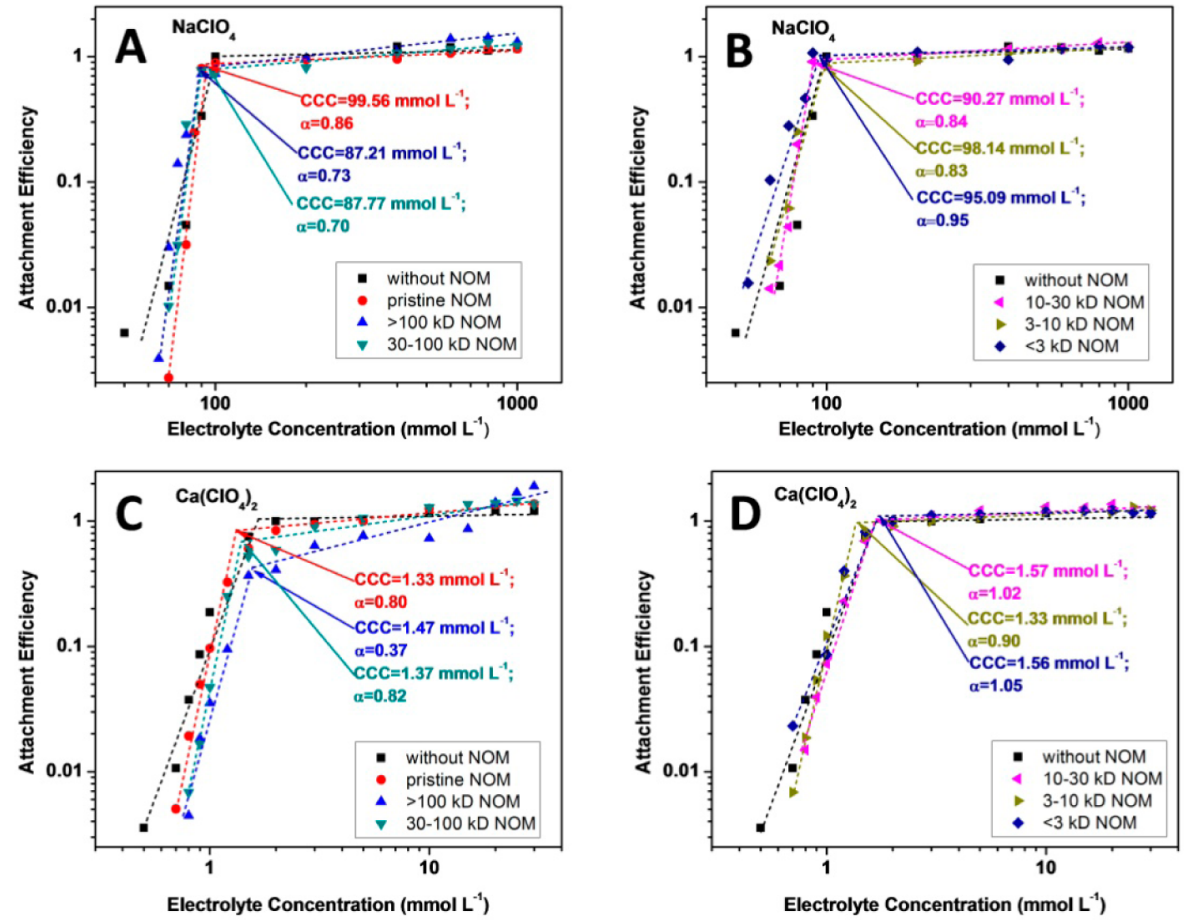

Figure 4. Attachment efficiency of Cit-AgNPs as a function of $\mathrm{NaClO}_{4}(\mathrm{~A}, \mathrm{~B})$ and $\mathrm{Ca}\left(\mathrm{ClO}_{4}\right)_{2}(\mathrm{C}, \mathrm{D})$ concentration in the presence of pristine-NOM and $\mathrm{M}_{\mathrm{f}} \mathrm{NOMs}$. Data for "without NOM" are given to facilitate the comparison of differences of $\alpha$ values among no SRNOM, pristine-, and $\mathrm{M}_{\mathrm{f}} \mathrm{NOM}$ solutions.

through both regimes, ${ }^{21}$ in $\mathrm{NaClO}_{4}$ solutions, were 447.27, 109.68, and $8.10 \mathrm{mmol} \mathrm{L}^{-1}$ for PVP-, Cit-, and Bare-AgNPs, respectively. The CCCs in $\mathrm{Ca}\left(\mathrm{ClO}_{4}\right)_{2}$ solutions were 15.56, 1.51, and $1.06 \mathrm{mmol} \mathrm{L}^{-1}$ for of PVP-, Cit- and Bare-AgNPs, respectively. The much lower CCCs of AgNPs in $\mathrm{Ca}\left(\mathrm{ClO}_{4}\right)_{2}$ solutions was ascribed to the stronger charge neutralization ability of the divalent electrolyte. ${ }^{24}$ From CCCs, we can clearly see PVP-AgNPs were more stable than Cit-AgNPs and BareAgNPs in both mono- and divalent electrolyte solutions. The zeta-potentials of the AgNPs were determined as -23.0, -47.0, and $-21.9 \mathrm{mV}$, for PVP-, Cit-, and Bare-AgNPs, respectively. The negative charge of PVP-AgNPs possibly origins from the adsorption of the residual side products on AgNPs. ${ }^{21}$ Similarly, the negative charge of Bare-AgNPs possibly origins from the adsorption of borate, the decomposition product from $\mathrm{KBH}_{4}$. As shown by the zeta-potentials, the better stability of PVPAgNPs than that of Cit-AgNPs cannot be explained only by electrostatic interaction. ${ }^{35}$ Steric hindrance, provided by PVP polymer, should also play important role in stabilizing PVPAgNPs. ${ }^{21}$ The CCCs of PVP-AgNPs in this study were much higher than that in Huynh et al's results, ${ }^{21}$ The following two facts possibly contributed the high stability of PVP-AgNPs in our work: (i) As revealed by TOC analysis, the PVP-AgNPs in our work have more coverage of PVP $(1.7 \mathrm{mg} \mathrm{PVP} / \mathrm{mg} \mathrm{Ag}$ ) than that in Huynh et al's $(0.8 \mathrm{mg} \mathrm{PVP} / \mathrm{mg} \mathrm{Ag})$; (ii) The PVP used in our work has higher average $\mathrm{MW}(58 \mathrm{kDa})$ than that in Huynh et al's $(10 \mathrm{kDa})$. Generally, synthetic polymer with higher MW could induce higher steric stabilization compared to that of their lower MW counterpart. ${ }^{36}$

Aggregation of AgNPs in Electrolyte Solution with Pristine and $\mathbf{M}_{\mathrm{f}}-\mathrm{NOM}$. PVP-AgNP. In the presence of $1 \mathrm{mg} \mathrm{C}$ $\mathrm{L}^{-1}$ pristine $\mathrm{NOM}$ and $\mathrm{NaClO}_{4}$, the $\mathrm{CCC}$ and the corresponding $\alpha$ of PVP-AgNPs was shifted to $320.5 \mathrm{mmol}$ $\mathrm{L}^{-1}$ and 1.67 , respectively (Figure $3 \mathrm{~A}$ ). Although the CCC value in the presence of pristine NOM slightly decreased relative to that without NOM (from 447.27 to $320.5 \mathrm{mmol}$ $\mathrm{L}^{-1}$ ), the corresponding $\alpha$ increased from 1 to 1.67 , indicating enhanced aggregation kinetics of PVP-AgNP in the presence of pristine NOM. Previous study also observed that $>2 \mathrm{mg} \mathrm{C} \mathrm{L}^{-1}$ Pony Lake fulvic acid could induce the rapid aggregation of gold nanoparticles in the presence of $80 \mathrm{mmol} \mathrm{L}^{-1} \mathrm{KCl}^{37}$

The aggregation of PVP-AgNPs was observed highly dependent on the MW of $\mathrm{M}_{\mathrm{f}} \mathrm{NOM}$. High MW NOM fraction (>100 $\mathrm{kDa}$ and $30-100 \mathrm{kDa} \mathrm{NOM}$ ) significantly enhanced the aggregation of PVP-AgNPs in $\mathrm{NaClO}_{4}$ solution (Figure 3A), while in the presence of low MW NOM fraction $(10-30 \mathrm{kDa}$, $3-10 \mathrm{kDa}$, and $<3 \mathrm{kDa} \mathrm{NOM}$ ) the aggregation of PVP-AgNPs was inhibited (Figure 3B). This MW-dependent aggregation and dispersion of PVP-AgNPs was also observed in $\mathrm{Ca}\left(\mathrm{ClO}_{4}\right)_{2}$ solution (Figure 3C and D). The zeta potentials of PVP-AgNP in the absence and presence of NOM in electrolyte solution were given in Supporting Information Figure S4, which shows that the zeta potential was generally more negative in the presence of NOM, with or without mono/divalent electrolytes. This result suggested that the electrosteric repulsion between nanoparticles increased by the adsorption of NOM on PVPAgNPs. In addition, the zeta potentials of PVP-AgNP were more negative when the concentration of $\mathrm{Ca}\left(\mathrm{ClO}_{4}\right)_{2}$ increased from 5 to $20 \mathrm{mmol} \mathrm{L}^{-1}$, indicating the increased adsorption of NOM on PVP-AgNPs. The interaction between $\mathrm{Ca}^{2+}$ and NOM could potentially alter the charges of NOM, ${ }^{38-40}$ which in turn affect the adsorption of NOM on AgNPs. As the content of carboxyl group was much lower in high MW NOM fraction, similar zeta potential of PVP-AgNPs in the presence $\mathrm{M}_{\mathrm{f}} \mathrm{NOM}$ indicated that the adsorption of high $\mathrm{MW} \mathrm{M}_{\mathrm{f}} \mathrm{NOM}$ should be higher than that low MW counterpart. ${ }^{17,37}$ As the concentration of NOM in this study was too low $\left(1 \mathrm{mg} \mathrm{L}^{-1}\right)$, measurement of the NOM amount adsorbed on AgNPs was 

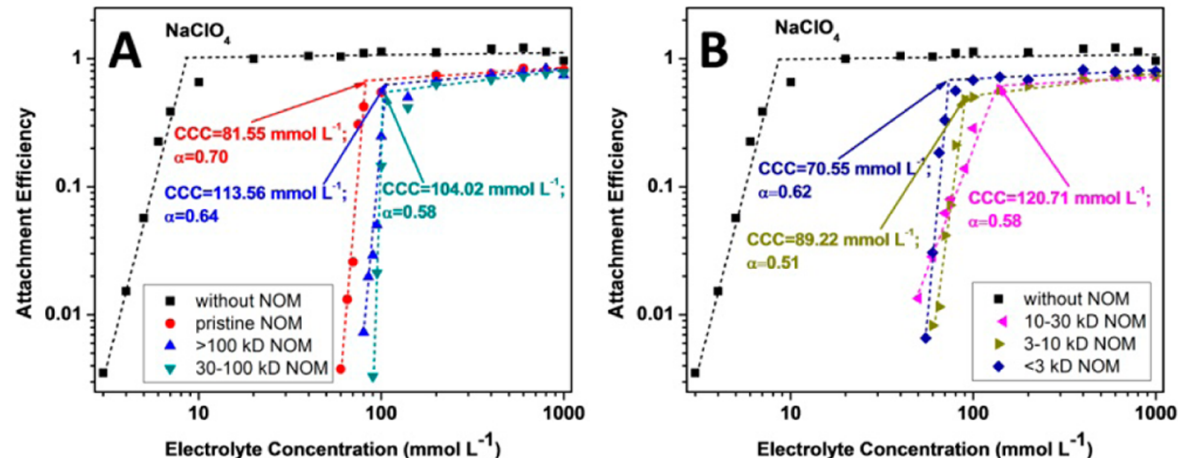

Electrolyte Concentration ( $\mathrm{mmol} \mathrm{L}^{-1}$ )
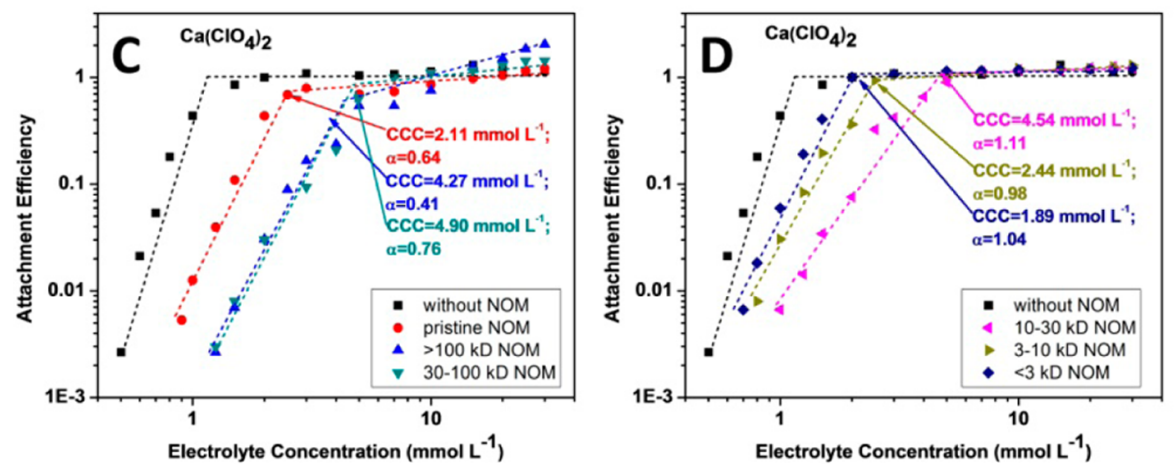

Figure 5. Attachment efficiency of Bare-AgNPs as a function of $\mathrm{NaClO}_{4}(\mathrm{~A}, \mathrm{~B})$ and $\mathrm{Ca}\left(\mathrm{ClO}_{4}\right)_{2}$ (C, D) concentration in the presence of pristine$\mathrm{NOM}$ and $\mathrm{M}_{\mathrm{f}} \mathrm{NOMs}$. Data for "without NOM" are given to facilitate the comparison of differences of $\alpha$ values among no SRNOM, pristine- and $\mathrm{M}_{\mathrm{f}}$ NOM solutions.

difficult. Generally, the aggregation of nanoparticles was determined by the electrostatic and steric repulsion. The overcoating or displacement of high $\mathrm{MW} \mathrm{M}_{\mathrm{f}}-\mathrm{NOM}$ although increased the interparticle electrostatic repulsion, but possibly decreased the steric repulsion by screening PVP. From Supporting Information Figure S4, we can see that, with more negative zeta potential, the electrostatic repulsion between PVP-AgNPs should increase in the presence of $>100$ $\mathrm{kDa} \mathrm{M}_{\mathrm{f}} \mathrm{NOM}$. However, the aggregation of PVP-AgNPs was enhanced in the presence of $>100 \mathrm{kDa} \mathrm{M}_{\mathrm{f}} \mathrm{NOM}$, which suggested that the presence of $>100 \mathrm{kDa} \mathrm{M}_{\mathrm{f}} \mathrm{NOM}$ decreased the steric repulsion between PVP-AgNPs. Thus, considering both the electrostatic and steric repulsion, high $\mathrm{MW} \mathrm{M}_{\mathrm{f}} \mathrm{NOM}$ accelerated the aggregation of PVP-AgNPs. However, low MW $\mathrm{M}_{\mathrm{f}} \mathrm{NOM}$ could adsorb on PVP-AgNPs surface but not screen PVP significantly, which result in enhanced electrostatic repulsion but minor change of steric repulsion. Therefore, low MW $\mathrm{M}_{\mathrm{f}} \mathrm{NOM}$ inhibited the aggregation of PVP-AgNPs. The detailed mechanism should be studied in the future via advanced characterization technique (such as microscale thermogravimetric analysis) ${ }^{41}$ to further elucidate the role of $\mathrm{M}_{\mathrm{f}}$-NOM on nanoparticle aggregation.

Cit-AgNP. The aggregation of Cit-AgNPs in both mono- and divalent electrolytes was not significantly influenced by pristine and $\mathrm{M}_{\mathrm{f}} \mathrm{NOM}$, compared with PVP-AgNPs (Figure 4). Specially, the aggregation of Cit-AgNPs was inhibited in the presence of $>100 \mathrm{kDa}$ NOM and low concentration of $\mathrm{Ca}^{2+}$, and an enhanced aggregation of Cit-AgNPs was observed in the presence of high MW $\mathrm{M}_{\mathrm{f}} \mathrm{NOM}$ ( $>100 \mathrm{kDa}$ and $30-100 \mathrm{kDa}$ NOM) and high concentration of $\mathrm{Ca}^{2+}$ (Figure 4C). The zeta potentials of Cit-AgNPs in electrolyte solution (Supporting Information Figure S5) showed that the zeta potential was also not significantly varied in the presence of pristine and $M_{f}$ NOM, with or without mono/divalent electrolytes. This should be ascribed to the inhibition of NOM adsorption on AgNPs by the electrostatic repulsion between NOM and coated citrate. The inhibition of aggregation by $>100 \mathrm{kDa}$ NOM should be ascribed to the steric repulsion provided by adsorbed NOM, whereas the enhancement of aggregation by high $\mathrm{MW} \mathrm{M}_{\mathrm{f}}$ NOM ( $>100 \mathrm{kDa}$ and $30-100 \mathrm{kDa}$ NOM) in the presence of high concentration of $\mathrm{Ca}^{2+}$ was ascribed to the interparticle bridging of NOM. ${ }^{21}$

Bare-AgNP. The aggregation of Bare-AgNPs in both monoand divalent electrolytes was significantly inhibited by pristine NOM (Figure 5). The CCCs were shifted from 8.10 and 1.06 mmol L ${ }^{-1}$ to 81.55 and $2.11 \mathrm{mmol} \mathrm{L}^{-1}$ in $\mathrm{NaClO}_{4}$ and $\mathrm{Ca}(\mathrm{ClO} 4)_{2}$, respectively (Figure 5A and $\mathrm{C}$ ). Accordingly, the $\alpha$ value in the presence of pristine NOM decreased to 0.70 and 0.64 in $\mathrm{NaClO}_{4}$ and $\mathrm{Ca}(\mathrm{ClO} 4)_{2}$, respectively.

In the presence of $\mathrm{M}_{\mathrm{f}} \mathrm{NOM}$, the aggregation of Bare-AgNPs in both mono- and divalent electrolytes was also inhibited significantly (Figure 5). Generally, this inhibition effect was correlated with the MW of $\mathrm{M}_{\mathrm{f}} \mathrm{NOM}$. High $\mathrm{MW} \mathrm{M}_{\mathrm{f}} \mathrm{NOM}$ could disperse Bare-AgNPs much better than low MW counterpart. This MW-dependent dispersion of nanoparticle by $\mathrm{M}_{\mathrm{f}} \mathrm{NOM}$ was also observed previously for fullerene ${ }^{18}$ and citrate-coated gold nanopartiles. ${ }^{17}$ High adsorption and strong steric repulsion of high MW $\mathrm{M}_{\mathrm{f}} \mathrm{NOM}$ possibly account for this MW-dependent dispersion. ${ }^{17}$ Compared with Cit-AgNPs, $\mathrm{M}_{\mathrm{f}^{-}}$ NOM, with the same MW enhanced the stabilization of BareAgNPs more effectively, possibly owning to different adsorption amount of $\mathrm{M}_{\mathrm{f}} \mathrm{NOM}$ on AgNPs. This result also supports our previous hypothesis that the electrostatic repulsion between NOM and coated citrate decreases the adsorption of $\mathrm{M}_{\mathrm{f}} \mathrm{NOM}$ on Cit-AgNPs. Additionally, when the concentration of $\mathrm{Ca}^{2+}$ were higher than $10 \mathrm{mmol} \mathrm{L}^{-1}$, enhanced aggregation of Bare-AgNPs was observed in pristine and high MW $\mathrm{M}_{\mathrm{f}} \mathrm{NOM}$ (>100 kDa and 30-100 kDa NOM) (Figure 
5C). However, this enhanced aggregation was not significant for low MW $\mathrm{M}_{\mathrm{f}} \mathrm{NOM}(10-30 \mathrm{kDa}, 3-10 \mathrm{kDa}$, and $<3 \mathrm{kDa}$ NOM) (Figure 5D). This enhanced aggregation of Bare-AgNPs was also correlated with the $\mathrm{MW}$ of $\mathrm{M}_{\mathrm{f}} \mathrm{NOM}$. The fraction of $>100 \mathrm{kDa}$ NOM enhanced aggregation more significantly than other fractions, followed by fraction of $30-100 \mathrm{kDa} \mathrm{M}_{\mathrm{f}} \mathrm{NOM}$. Previous studies also observed enhanced aggregation of fullerene, ${ }^{42}$ gold, ${ }^{43}$ silver, ${ }^{21}$ nano zerovalent iron, ${ }^{44} \mathrm{CeO}_{2}$, ${ }^{45}$ and silicon nanoparticles, ${ }^{46}$ in the presence of high concentration of $\mathrm{Ca}^{2+}$, which were possibly induced by the $\mathrm{Ca}^{2+}$ induced interparticle bridging of NOM adsorbed on nanoparticles. $^{42}$ However, how specific compositions in NOM behave in this enhanced aggregation is still not well clarified. The findings of MW-dependent aggregation in the presence of high concentration of $\mathrm{Ca}^{2+}$ in our study, suggested that previous observation of this enhanced aggregation should be mainly ascribed to the high MW fraction of NOM.

The zeta potentials of Bare-AgNPs in the absence and presence of NOM in electrolyte solution were given in Supporting Information Figure S6. The results clearly showed that the zeta potential of Bare-AgNPs was more negative in the presence of pristine and $\mathrm{M}_{\mathrm{f}} \mathrm{NOM}$, with or without mono/ divalent electrolytes. The zeta potential of Bare-AgNPs in the presence of $>100 \mathrm{kDa} N \mathrm{NOM}$ was even more negative than that in the presence of $<3 \mathrm{kDa}$ NOM. As the high MW NOM fraction contained less carboxyl group and negative charge than low MW NOM, ${ }^{47}$ the adsorption of high MW NOM fraction should be much higher than low MW NOM. Similar preferential adsorption of high MW and aromatic NOM fraction was also observed on mineral surfaces by size exclusion chromatography ${ }^{48-50}$ and ${ }^{13} \mathrm{C}$-nuclear magnetic resonance analysis. ${ }^{51}$ These results indicated hydrophobic interaction between NOM and nanoparticles is the main driving force influencing the adsorption behavior of NOM. The electrostatic repulsion provided by adsorbed NOM could disperse BareAgNPs. In addition, the steric repulsion from high $\mathrm{MW} \mathrm{M}_{\mathrm{f}}$ NOM was stronger than that from low MW fractions, ${ }^{17}$ which resulted in better dispersion of Bare-AgNPs in high MW $\mathrm{M}_{\mathrm{f}}$ NOM.

The synthetical results of the $\mathrm{M}_{\mathrm{f}} \mathrm{NOM}$ on the aggregation of Bare-, Cit-, and PVP-AgNP in electrolyte suggested that the natures of both coating agent and the $\mathrm{M}_{\mathrm{f}} \mathrm{NOM}$ have great impacts on the aggregation of AgNP. If the stabilization effect of $\mathrm{M}_{\mathrm{f}} \mathrm{NOM}$ is weaker than that of the coating agent (e.g., >100 $\mathrm{kDa} \mathrm{M}_{\mathrm{f}} \mathrm{NOM}$ in the case of PVP-AgNP), the overcoating or displacing of the coating agent by $\mathrm{M}_{\mathrm{f}} \mathrm{NOM}$ could generally accelerate the aggregation. However, if the adsorbed $\mathrm{M}_{\mathrm{f}} \mathrm{NOM}$ could provide additional repulsion (e.g., electrostatic repulsion from $<3 \mathrm{kDa} \mathrm{M}_{\mathrm{f}} \mathrm{NOM}$ in the case of PVP-AgNP), $\mathrm{M}_{\mathrm{f}}-\mathrm{NOM}$ could still inhibit the aggregation. If the stabilization effect of $\mathrm{M}_{\mathrm{f}} \mathrm{NOM}$ is stronger than that of the coating agent (e.g., $\mathrm{M}_{\mathrm{f}}$ NOM in the case of Bare-AgNP), the adsorbed $\mathrm{M}_{\mathrm{f}} \mathrm{NOM}$ could generally inhibit the aggregation. The differential stabilization effects of $\mathrm{M}_{\mathrm{f}}-\mathrm{NOM}$ on nanoparticle were ascribed to their provided electrostatic and steric repulsions. Generally, the steric repulsion from high $\mathrm{MW} \mathrm{M}_{\mathrm{f}} \mathrm{NOM}$ are stronger than that from low $\mathrm{MW} \mathrm{M}_{\mathrm{f}} \mathrm{NOM}$, as the steric force arise due to the osmotic pressure when polymer chains are compressed. ${ }^{36,52}$ To further support the hypothesis of higher steric force from high $\mathrm{MW} \mathrm{M}_{\mathrm{f}}$ NOM, AFM was used to probe the force from different $M_{f}$ NOM. The result (Supporting Information Figure S7) showed that at a short separation distance the repulsive force between the AFM tip and silver foil in the presence of $>100 \mathrm{kDa} \mathrm{M}_{\mathrm{f}}$
NOM is higher than that of $<3 \mathrm{kDa} \mathrm{M}_{\mathrm{f}} \mathrm{NOM}$, indicating higher steric repulsion provided by high MW NOM. ${ }^{28,52}$ This result demonstrated that, besides electrostatic repulsion, NOM could also provide short ranged steric repulsion, and the steric repulsion from high MW NOM is much higher than that from lower MW NOM.

Environmental Implications. The aggregation or dispersion of engineered AgNPs is influenced by the coating type of AgNPs. The engineered AgNPs in commercial nanoproducts are often coated with organic compounds with varying functional groups, ${ }^{7}$ which will influence their transport and transformation once released into the environment. In this study, we demonstrated that coating of AgNPs has distinguishing impact on the aggregation or dispersion of AgNPs in both pristine NOM and $\mathrm{M}_{\mathrm{f}} \mathrm{NOM}$. This finding highlights that AgNPs with different coating will behave differently even in the same environmental settings. The evaluation of different coating on the fate of AgNPs is necessary in the future study.

MW of NOM is another controlling factor influencing the aggregation of engineered AgNPs. Considering low concentration of NOM $\left(1 \mathrm{mg} \mathrm{C} \mathrm{L}^{-1}\right)$ used in this study, NOM should play important role in the aggregation or dispersion of AgNPs in a real aquatic compartment. The finding of accelerated aggregation of PVP-AgNPs with high MW fraction of NOM, even without divalent cation, suggests that the role of NOM in nanoparticle aggregation is complicated than what we previously expected. The MW-dependent aggregation and dispersion of AgNPs reveals that different fractions in NOM from real water will behave much differently toward nanoparticles. In addition, as the MW composition of different sourced NOM is much different and physical or chemical processes (such as adsorption on mineral and photochemical decomposition) could also change the MW distribution of NOM from the same source, ${ }^{48,53-56}$ the MW composition of NOM in the environmental water should be considered in the assessment of NOM on nanoparticle aggregation. Moreover, the $\mathrm{MW}$-dependent adsorption of $\mathrm{M}_{\mathrm{f}} \mathrm{NOM}$ on nanoparticle and the effect of $\mathrm{pH}$ and concentration of $\mathrm{M}_{\mathrm{f}} \mathrm{NOM}$ on the aggregation should be investigated in the future to further elucidate the complicated role of NOM in transport and subsequent transformation of nanoparticles. Besides MW, functional groups (such as thiol, amino group) in different sourced and fractionated NOM could also play important role in the dispersion of nanoparticles, ${ }^{57}$ which further emphasizes that the comprehensive characterization and knowledge of $\mathrm{NOM}$ are required for predicting the behavior of nanoparticles in environmental waters.

\section{ASSOCIATED CONTENT}

\section{Supporting Information}

Additional results are provided in Supporting Information. The Supporting Information is available free of charge on the ACS Publications website at DOI: 10.1021/es5061287.

\section{AUTHOR INFORMATION}

\section{Corresponding Author}

*Phone: +86-10-62849192; fax: +86-10-62849192; e-mail: jfliu@rcees.ac.cn.

\section{Notes}

The authors declare no competing financial interest. 


\section{ACKNOWLEDGMENTS}

This work was supported by the Strategic Priority Research Program of the Chinese Academy of Sciences (XDB14020101), the National Basic Research Program of China (2015CB932003), the National Natural Science Foundation of China (21337004), External Cooperation Program of Chinese Academy of Sciences (GJHZ1206), and Young Scientists Fund of RCEES (RCEES-QN-20130028F). We thank Miss Mingfang Wang in the Beijing National Center for Electron Microscopy for TEM characterizations.

\section{REFERENCES}

(1) Project on Emerging Nanotechnologies (2014). Consumer Products Inventory. http://www.nanotechproject.org/cpi (accessed April 10, 2014).

(2) Benn, T.; Cavanagh, B.; Hristovski, K.; Posner, J. D.; Westerhoff, $\mathrm{P}$. The release of nanosilver from consumer products used in the home. J. Environ. Qual. 2010, 39 (6), 1875-1882.

(3) Benn, T. M.; Westerhoff, P. Nanoparticle silver released into water from commercially available sock fabrics. Environ. Sci. Technol. 2008, 42 (11), 4133-4139.

(4) Kaegi, R.; Sinnet, B.; Zuleeg, S.; Hagendorfer, H.; Mueller, E.; Vonbank, R.; Boller, M.; Burkhardt, M. Release of silver nanoparticles from outdoor facades. Environ. Pollut. 2010, 158 (9), 2900-2905.

(5) Quadros, M. E.; Marr, L. C. Silver nanoparticles and total aerosols emitted by nanotechnology-related consumer spray products. Environ. Sci. Technol. 2011, 45 (24), 10713-10719.

(6) Quadros, M. E.; Pierson, R.; Tulve, N. S.; Willis, R.; Rogers, K.; Thomas, T. A.; Marr, L. C. Release of silver from nanotechnologybased consumer products for children. Environ. Sci. Technol. 2013, 47 (15), 8894-8901.

(7) Levard, C.; Hotze, E. M.; Lowry, G. V.; Brown, G. E. Environmental transformations of silver nanoparticles: Impact on stability and toxicity. Environ. Sci. Technol. 2012, 46 (13), 6900-6914.

(8) Lau, B. L. T.; Hockaday, W. C.; Ikuma, K.; Furman, O.; Decho, A. W. A preliminary assessment of the interactions between the capping agents of silver nanoparticles and environmental organics. Colloid Surf., A 2013, 435, 22-27.

(9) Fabrega, J.; Fawcett, S. R.; Renshaw, J. C.; Lead, J. R. Silver nanoparticle impact on bacterial growth: Effect of $\mathrm{pH}$, concentration, and organic matter. Environ. Sci. Technol. 2009, 43 (19), 7285-7290. (10) MacCuspie, R. I.; Rogers, K.; Patra, M.; Suo, Z. Y.; Allen, A. J.; Martin, M. N.; Hackley, V. A. Challenges for physical characterization of silver nanoparticles under pristine and environmentally relevant conditions. J. Environ. Monit. 2011, 13 (5), 1212-1226.

(11) Chinnapongse, S. L.; MacCuspie, R. I.; Hackley, V. A. Persistence of singly dispersed silver nanoparticles in natural freshwaters, synthetic seawater, and simulated estuarine waters. Sci. Total Environ. 2011, 409 (12), 2443-2450.

(12) Delay, M.; Dolt, T.; Woellhaf, A.; Sembritzki, R.; Frimmel, F. H. Interactions and stability of silver nanoparticles in the aqueous phase: Influence of natural organic matter (NOM) and ionic strength. J. Chromatogr. A 2011, 1218 (27), 4206-4212.

(13) Zhang, H. Y.; Smith, J. A.; Oyanedel-Craver, V. The effect of natural water conditions on the anti-bacterial performance and stability of silver nanoparticles capped with different polymers. Water Res. 2012, 46 (3), 691-699.

(14) Baalousha, M.; Nur, Y.; Romer, I.; Tejamaya, M.; Lead, J. R. Effect of monovalent and divalent cations, anions and fulvic acid on aggregation of citrate-coated silver nanoparticles. Sci. Total Environ. 2013, 454, 119-131.

(15) Akaighe, N.; Depner, S. W.; Banerjee, S.; Sharma, V. K.; Sohn, $M$. The effects of monovalent and divalent cations on the stability of silver nanoparticles formed from direct reduction of silver ions by Suwannee River humic acid/natural organic matter. Sci. Total Environ. 2012, 441, 277-289.
(16) Mostofa, K. M. G.; Liu, C. Q.; Mottaleb, M. A.; Wan, G. J.; Ogawa, H.; Vione, D.; Yoshioka, T.; Wu, F. C. Dissolved organic matter in natural waters. In Photobiogeochemistry of Organic Matter: Principles and Practices in Water Environments; Mostofa, K. M. G.; Yoshioka, T.; Mottaleb, M. A.; Vione, D., Ed.; Springer, 2013.

(17) Louie, S. M.; Tilton, R. D.; Lowry, G. V. Effects of molecular weight distribution and chemical properties of natural organic matter on gold nanoparticle aggregation. Environ. Sci. Technol. 2013, 47 (9), $4245-4254$.

(18) Shen, M. H.; Yin, Y. G.; Liu, J. F.; Booth, A. Effects of molecular weight-dependent physicochemical heterogeneity of natural organic matter on the aggregation of fullerene nanoparticles in mono- and divalent electrolyte solutions. Water Res. 2015, 71, 11-20.

(19) Furman, O.; Usenko, S.; Lau, B. L. T. Relative importance of the humic and fulvic fractions of natural organic matter in the aggregation and deposition of silver nanoparticles. Environ. Sci. Technol. 2013, 47 (3), 1349-1356.

(20) Yin, Y. G.; Shen, M. H.; Zhou, X. X.; Yu, S. J.; Chao, J. B.; Liu, J. F.; Jiang, G. B. Photoreduction and stabilization capability of molecular weight fractionated natural organic matter in transformation of silver ion to metallic nanoparticle. Environ. Sci. Technol. 2014, 48 (16), 9366-9373.

(21) Huynh, K. A.; Chen, K. L. Aggregation kinetics of citrate and polyvinylpyrrolidone coated silver nanoparticles in monovalent and divalent electrolyte solutions. Environ. Sci. Technol. 2011, 45 (13), $5564-5571$

(22) El Badawy, A. M.; Hassan, A. A.; Scheckel, K. G.; Suidan, M. T.; Tolaymat, T. M. Key factors controlling the transport of silver nanoparticles in porous media. Environ. Sci. Technol. 2013, 47 (9), 4039-4045.

(23) Thio, B. J. R.; Montes, M. O.; Mahmoud, M. A.; Lee, D. W.; Zhou, D. X.; Keller, A. A. Mobility of capped silver nanoparticles under environmentally relevant conditions. Environ. Sci. Technol. 2012, 46 (13), 6985-6991.

(24) El Badawy, A. M.; Scheckel, K. G.; Suidan, M.; Tolaymat, T. The impact of stabilization mechanism on the aggregation kinetics of silver nanoparticles. Sci. Total Environ. 2012, 429, 325-331.

(25) Tejamaya, M.; Romer, I.; Merrifield, R. C.; Lead, J. R. Stability of citrate, PVP, and PEG coated silver nanoparticles in ecotoxicology media. Environ. Sci. Technol. 2012, 46 (13), 7011-7017.

(26) Yu, S. J.; Yin, Y. G.; Chao, J. B.; Shen, M. H.; Liu, J. F. Highly dynamic PVP-coated silver nanoparticles in aquatic environments: Chemical and morphology change induced by oxidation of $\mathrm{Ag}^{\mathrm{O}}$ and reduction of $\mathrm{Ag}^{+}$. Environ. Sci. Technol. 2014, 48 (1), 403-411.

(27) Kim, J. S.; Kuk, E.; Yu, K. N.; Kim, J. H.; Park, S. J.; Lee, H. J.; Kim, S. H.; Park, Y. K.; Park, Y. H.; Hwang, C. Y.; Kim, Y. K.; Lee, Y. S.; Jeong, D. H.; Cho, M. H. Antimicrobial effects of silver nanoparticles. Nanomed. Nanotechnol. 2007, 3 (1), 95-101.

(28) Liu, D.; Peng, Y. J. Understanding different roles of lignosulfonate in dispersing clay minerals in coal flotation using deionised water and saline water. Fuel 2015, 142, 235-242.

(29) Wu, F. C.; Evans, R. D.; Dillon, P. J. Separation and characterization of NOM by high-performance liquid chromatography and on-line three-dimensional excitation emission matrix fluorescence detection. Environ. Sci. Technol. 2003, 37 (16), 3687-3693.

(30) Peuravuori, J.; Pihlaja, K. Molecular size distribution and spectroscopic properties of aquatic humic substances. Anal. Chim. Acta 1997, 337 (2), 133-149.

(31) Chin, Y. P.; Aiken, G.; Oloughlin, E. Molecular-weight, polydispersity, and spectroscopic properties of aquatic humic substances. Environ. Sci. Technol. 1994, 28 (11), 1853-1858.

(32) Richard, C.; Guyot, G.; Rivaton, A.; Trubetskaya, O.; Trubetskoj, O.; Cavani, L.; Ciavatta, C. Spectroscopic approach for elucidation of structural peculiarities of Andisol soil humic acid fractionated by SEC-PAGE setup. Geoderma 2007, 142 (1-2), 210216.

(33) Huang, H. H.; Ni, X. P.; Loy, G. L.; Chew, C. H.; Tan, K. L.; Loh, F. C.; Deng, J. F.; Xu, G. Q. Photochemical formation of silver 
nanoparticles in poly(N-vinylpyrrolidone). Langmuir 1996, 12 (4), 909-912.

(34) Kumar, M.; Reddy, G. B. Effect of atmospheric exposure on the growth of citrate-capped silver nanoparticles. Physica E 2010, 42 (7), 1940-1943.

(35) Sun, Z.; Nicolosi, V.; Rickard, D.; Bergin, S. D.; Aherne, D.; Coleman, J. N. Quantitative evaluation of surfactant-stabilized singlewalled carbon nanotubes: Dispersion quality and its correlation with zeta potential. J. Phys. Chem. C 2008, 112 (29), 10692-10699.

(36) Ghosh, S.; Jiang, W.; McClements, D. J.; Xing, B. S. Colloidal stability of magnetic iron oxide nanoparticles: Influence of natural organic matter and synthetic polyelectrolytes. Langmuir 2011, 27 (13), 8036-8043.

(37) Nason, J. A.; McDowell, S. A.; Callahan, T. W. Effects of natural organic matter type and concentration on the aggregation of citratestabilized gold nanoparticles. J. Environ. Monit. 2012, 14 (7), 18851892.

(38) Kloster, N.; Brigante, M.; Zanini, G.; Avena, M. Aggregation kinetics of humic acids in the presence of calcium ions. Colloid Surf., A 2013, 427, 76-82.

(39) Christl, I.; Kretzschmar, R. C-1s NEXAFS spectroscopy reveals chemical fractionation of humic acid by cation-induced coagulation. Environ. Sci. Technol. 2007, 41 (6), 1915-1920.

(40) Wang, L. F.; Wang, L. L.; Ye, X. D.; Li, W. W.; Ren, X. M.; Sheng, G. P.; Yu, H. Q.; Wang, X. K. Coagulation kinetics of humic aggregates in mono- and di-valent electrolyte solutions. Environ. Sci. Technol. 2013, 47 (10), 5042-5049.

(41) Mansfield, E.; Tyner, K. M.; Poling, C. M.; Blacklock, J. L. Determination of nanoparticle surface coatings and nanoparticle purity using microscale thermogravimetric analysis. Anal. Chem. 2014, 86 (3), $1478-1484$.

(42) Chen, K. L.; Elimelech, M. Influence of humic acid on the aggregation kinetics of fullerene (C-60) nanoparticles in monovalent and divalent electrolyte solutions. J. Colloid Interface Sci. 2007, 309 (1), 126-134.

(43) Stankus, D. P.; Lohse, S. E.; Hutchison, J. E.; Nason, J. A. Interactions between natural organic matter and gold nanoparticles stabilized with different organic capping agents. Environ. Sci. Technol. 2011, 45 (8), 3238-3244.

(44) Dong, H. R.; Lo, I. M. C. Influence of calcium ions on the colloidal stability of surface-modified nano zero-valent iron in the absence or presence of humic acid. Water Res. 2013, 47 (7), 24892496.

(45) Li, K. G.; Chen, Y. S. Effect of natural organic matter on the aggregation kinetics of $\mathrm{CeO}_{2}$ nanoparticles in $\mathrm{KCl}$ and $\mathrm{CaCl}_{2}$ solutions: Measurements and modeling. J. Hazard. Mater. 2012, 209, 264-270.

(46) Liu, X. Y.; Wazne, M.; Chou, T. M.; Xiao, R.; Xu, S. Y. Influence of $\mathrm{Ca}^{2+}$ and Suwannee River humic acid on aggregation of silicon nanoparticles in aqueous media. Water Res. 2011, 45 (1), 105-112.

(47) Christl, I.; Kretzschmar, R. Relating ion binding by fulvic and humic acids to chemical composition and molecular size. 1. Proton binding. Environ. Sci. Technol. 2001, 35 (12), 2505-2511.

(48) Gu, B. H.; Schmitt, J.; Chen, Z.; Liang, L. Y.; Mccarthy, J. F. Adsorption and desorption of different organic-matter fractions on iron-oxide. Geochim. Cosmochim. Acta 1995, 59 (2), 219-229.

(49) Meier, M.; Namjesnik-Dejanovic, K.; Maurice, P. A.; Chin, Y. P.; Aiken, G. R. Fractionation of aquatic natural organic matter upon sorption to goethite and kaolinite. Chem. Geol. 1999, 157 (3-4), 275284.

(50) Wang, L. L.; Chin, Y. P.; Traina, S. J. Adsorption of (poly)maleic acid and an aquatic fulvic acid by goethite. Geochim. Cosmochim. Acta 1997, 61 (24), 5313-5324.

(51) Wang, K. J.; Xing, B. S. Structural and sorption characteristics of adsorbed humic acid on clay minerals. J. Environ. Qual. 2005, 34 (1), 342-349.

(52) Pensini, E.; Sleep, B. E.; Yip, C. M.; O’Carroll, D. Forces of interactions between iron and aluminum silicates: Effect of water chemistry and polymer coatings. J. Colloid Interface Sci. 2013, 411, 815 .

(53) Ratnaweera, H.; Hiller, N.; Bunse, U. Comparison of the coagulation behavior of different Norwegian aquatic NOM sources. Environ. Int. 1999, 25 (2-3), 347-355.

(54) Marhaba, T. F.; Van, D.; Lippincott, R. L. Changes in NOM fractionation through treatment: A comparison of ozonation and chlorination. Ozone: Sci. Eng. 2000, 22 (3), 249-266.

(55) McCallister, S. L.; Bauer, J. E.; Kelly, J.; Ducklow, H. W. Effects of sunlight on decomposition of estuarine dissolved organic $\mathrm{C}, \mathrm{N}$ and $\mathrm{P}$ and bacterial metabolism. Aquat. Microb. Ecol. 2005, 40 (1), 25-35.

(56) Rosenstock, B.; Zwisler, W.; Simon, M. Bacterial consumption of humic and non-humic low and high molecular weight DOM and the effect of solar irradiation on the turnover of labile DOM in the Southern Ocean. Microb. Ecol. 2005, 50 (1), 90-101.

(57) Louie, S. M.; Spielman-Sun, E. R.; Small, M. J.; Tilton, R. D.; Lowry, G. V. Correlation of the physicochemical properties of natural organic matter samples from different sources to their effects on gold nanoparticle aggregation in monovalent electrolyte. Environ. Sci. Technol. 2015, 49 (4), 2188-2198. 